\title{
Relationships between road slipperiness, traffic accident risk and winter road maintenance activity
}

\author{
Jonas Norrman*, Marie Eriksson, Sven Lindqvist
}

Lab. of Climatology, Physical Geography, Dept. of Earth Sciences, Göteborg University, Box 460, 40530 Göteborg, Sweden

\begin{abstract}
A method for deriving quantitative relationships between road slipperiness, traffic accident risk and winter road maintenance (WRM) activity is described. The method is also applied to data from an area in southern Sweden. If a specific type of road slipperiness represents a large accident risk despite high WRM activity it is important to increase public awareness during such periods. If the type of slipperiness represents a large accident risk but is accompanied by low WRM activity, it is also important to increase the WRM to reduce the accident risk. In the method, a road slipperiness classification, based on atmospheric processes, is used to classify the road conditions at the time an accident occurred. The road condition is classified either as non-slippery or as one out of 10 types of slipperiness. Data for the slipperiness classification are taken from the Swedish Road Weather Information System (RWIS). Results from this study show that the traffic accident risk was different for different types of road slipperiness. Highest accident risk was associated with road slipperiness due to rain or sleet on a frozen road surface. When accidents occurred in these situations, there was always high WRM activity. This indicates that, in order to reduce the accident rate during these situations, public awareness must be increased by providing information to drivers. The study also demonstrates the benefits of applying a standardized road slipperiness classification to all kinds of sources of road safety information, such as a RWIS, traffic accident reports and WRM reports. With a standardized and objective classification of the road conditions and digitally stored data, all evaluations are easily conducted.
\end{abstract}

KEY WORDS: Road slipperiness · Traffic accidents · Winter road maintenance Resale or republication not permitted without written consent of the publisher

\section{INTRODUCTION}

Studies show that there is often a relationship between slippery road conditions and traffic accidents, even in areas where winter road maintenance (WRM) is performed (Schandersson 1988, Sävenhed 1995, Andreescu \& Frost 1998). For example, in Finland about $25 \%$ of all fatal accidents occur on icy or snowy road surfaces (Kulmala \& Rämä 1995). This is of serious concern, as improving slippery road conditions in order to reduce the number of traffic accidents is the main objective for WRM personnel.

\footnotetext{
*E-mail: jonas.norrman@gvc.gu.se
}

To detect slippery road conditions, WRM personnel use information from a Road Weather Information System (RWIS). The Swedish RWIS has more than 600 roadside stations equipped with sensors measuring several meteorological variables. The large number of stations, taking measurements twice an hour, produce information with both high temporal and high spatial resolution.

When slippery road conditions are forecasted, or have developed, proper maintenance action is taken, i.e. ploughing, gritting or both. However, even if the WRM organization is alerted and out working, it will take some time before the entire area is cleared. During this initial period there is a high risk for accidents to occur. For example, when snow first starts falling, 
more accidents happen, but after a while the rate stabilizes as people get used to the new road conditions (Öberg 1993, Sävenhed 1995).

The accident risk is also a function of the public awareness of the problem. Studies have shown that drivers are not good at adjusting the speed of their vehicle to the prevailing road conditions, even if the hazard is clearly visible (Öberg 1991, Wallman 1997). Wintertime road conditions also vary between areas and change with time. Johansson (1997) showed that the traffic accident rate during hazardous situations is higher in southern Sweden, where slipperiness on roads is more rare, than in Northern Sweden, where people are used to driving in winter road conditions. It is important for WRM personnel to know which type of road slipperiness has the highest accident risk in their area.

Previous studies of relationships between road slipperiness and risk of traffic accidents have used the standard road condition description in police reports (Fridstrøm et al. 1995, Sävenhed 1995, Johansson 1997, Edwards 1999). There are, however, many other types of road slipperiness than the standard descriptions used in police reports. Andreescu \& Frost (1998) used linear regression to explain the relationship between traffic accidents, snowfall, rain and mean temperature. There is a chance, though, that the conditions at the meteorological station are not the same as at the location of the accident. If possible, it is therefore better to use highresolution meteorological data such as the RWIS, since the road surface conditions may vary over short distances (Andrey \& Olley 1990, Gustavsson 1995).

If a relationship between traffic accidents and road slipperiness can be established, the WRM can be complimented with other measures to decrease the accident risk. For example, information about prevailing road conditions can be used in order to increase public awareness of the situation or to decrease the speed limit in the area according to the prevailing road condition.
When supplying drivers in Finland with information on road slipperiness it was shown that the average speed is reduced if warning signs are used (Kulmala \& Rämä 1995). In Sweden, no organized warning system is functional today but there are plans to develop a system. It is therefore important to investigate during which type of road conditions it is necessary to provide information to the driver to reduce the accident rate.

In order to know how to improve traffic safety it must be possible to derive quantitative relationships between WRM and traffic accident risk. A problem when quantifying such relationships is the comparison of the different types of slipperiness that may develop; maintenance procedures are different for each type. The possibility for drivers to detect hazardous road conditions also varies between types. For deriving quantitative relationships between road slipperiness, traffic accident risk and WRM activity it is necessary to distinguish between the different types.

This study presents a method for deriving quantitative relationships between road slipperiness, traffic accident risks and WRM activity in an area where WRM is performed to increase road safety. The method is applied to data from a region in southern Sweden.

An expert system developed by Norrman (1999) is used to classify road conditions automatically at the time of an accident as either 'not slippery' or as one out of 10 different types of slipperiness (Table 1). The classification is based on high-resolution meteorological data from RWIS stations located no further than $25 \mathrm{~km}$ from the location of an accident. The slipperiness classification is further described in Section 2.

The classified RWIS observations are then used to describe the road surface status at the time of a traffic accident. By using the slipperiness classification it is possible to categorize both WRM and traffic accidents by the type of road slipperiness.

The present study also demonstrates the benefits of applying a standardized road slipperiness classifica-

Table 1. The 10 different types of slipperiness on roads used in the study and the variables neccessary for expert system classification. The presence of precipitation is noted as either 'yes' or 'no'. $P$ : precipitation; $T_{\text {air, }} T_{\text {road, }} T_{\text {dew }}$ air, road and dewpoint temperatures; $R h$ : relative humidity; $U$ : wind speed

\begin{tabular}{|c|c|c|}
\hline Type of slipperiness & Precipitation & Variables \\
\hline (1) Precipitation (rain/sleet) on a frozen road surface & Yes & $P, T_{\text {air }}, T_{\text {road }}$ \\
\hline (2) Precipitation (snow) on a frozen road surface & Yes & $P, T_{\text {air }}, T_{\text {road }}$ \\
\hline (3) Precipitation (snow/sleet) on a warm road surface & Yes & $P, T_{\text {air }}, T_{\text {road }}$ \\
\hline (4) Snowfall together with hoarfrost & Yes & $P, T_{\text {air }}, T_{\text {road }}, T_{\text {dew }}$ \\
\hline (5) Hoarfrost and low visibility & No & $T_{\text {road }}, T_{\text {dew }}, R h$ \\
\hline (6) Freezing dew followed by hoarfrost & No & $T_{\text {road, }} T_{\text {dew }}$ \\
\hline (7) Strong formation of hoarfrost & No & $T_{\text {road }}, T_{\text {dew }}, R h, U$ \\
\hline (8) Weak formation of hoarfrost & No & $T_{\text {road }}, T_{\text {dew }} R h, U$ \\
\hline (9) Drifting snow & Yes & $P, T_{\text {air }} R h, U$ \\
\hline (10) Watercover which freezes & Yes & $P, T_{\text {air }}, T_{\text {dew }}, T_{\text {road }}, R h$ \\
\hline
\end{tabular}


tion to all kinds of road safety information, such as meteorological data, traffic accident reports and WRM reports. At present, only the descriptions of road conditions in the accident reports are standardized. The WRM reports used were hard to acquire and analyze as they are archived on paper by each individual WRM contractor. Due to these data restrictions RWIS data and traffic accident data from 3 winters, 1991-92, 199394 and 1995-96 (a total of 246 accidents), and WRM data from 2 winters, 1993-94 and 1995-96, were used.

\section{DATA AND METHODS}

The WRM personnel need information about the road conditions in their area that has high temporal and spatial resolution. To get this information, several countries have constructed a national RWIS. In the Swedish RWIS, a large number of field stations are situated at roadsides, each equipped with sensors measuring air temperature $\left(T_{\text {air }}\right)$, relative humidity $(R h)$ and road surface temperature $\left(T_{\text {road }}\right)$. Observations are made every $30 \mathrm{~min}$ and the data are collected and stored in a central archive. Some stations also observe precipitation $(P)$, wind speed $(U)$ and wind direction. The dewpoint temperature $\left(T_{\mathrm{dew}}\right)$ is automatically derived from $T_{\text {air }}$ and $R h$.

In this study, RWIS data from 2 stations, $70 \mathrm{~km}$ apart, were used to classify road conditions. The stations were chosen because both of them observe all variables necessary for the slipperiness classification. They are both situated in open and windexposed locations less than $10 \mathrm{~km}$ from the coast along highway E6 in the county of Halland (Fig. 1). The areas within a $25 \mathrm{~km}$ radius from each station define the North and South areas, in which traffic accidents were analyzed.

Road conditions at the time of an accident were classified in each area respectively as either not slippery road conditions or as one out of 10 types of slipperiness. The classification was performed with a computerized, knowledge-based expert system. In this type of expert system the main component of the knowledge base is a set of rules. The rules are built with logical statements that form a decision tree, from the input data to the output classification. The different types of slipperiness are presented in Table 1, together with the variables used in the rules for that specific type. It is impor- tant to emphasize that the classification is based on the variables available in the RWIS. An example of a problematic road condition that is not possible to detect by the RWIS is residual snow from an earlier snowfall on the road.

Six of the types of slipperiness in Table 1 are due to precipitation and the other 4 are due to sublimation. These 2 atmospheric processes are responsible for the transportation of water to the road surface. Frozen water is crucial, as it is the medium which reduces road friction to such a degree that the condition can be classified as slippery. If all the criteria for a certain type of slipperiness are fulfilled it means that there is meteorological potential for slipperiness on the road or that it will become slippery. Norrman (1999) further describes the construction of the slipperiness classification.

The first 4 types of slipperiness in Table 1 occur as a result of precipitation. The different types of slipperiness that develop during occasions with precipitation are identified in combination with other variables. The most important problem with these classification rules is that there is no way of recognizing freezing rain. During periods of freezing rain the air temperature may fall below $0^{\circ} \mathrm{C}$ and then the optical rain gauge will classify all precipitation as snow.

On occasions when snowfall and sublimation occur simultaneously (Type 4), water is transported towards the surface by 2 different processes. Snow sticks to the road surface due to the hoarfrost and the ice cover increases rapidly.

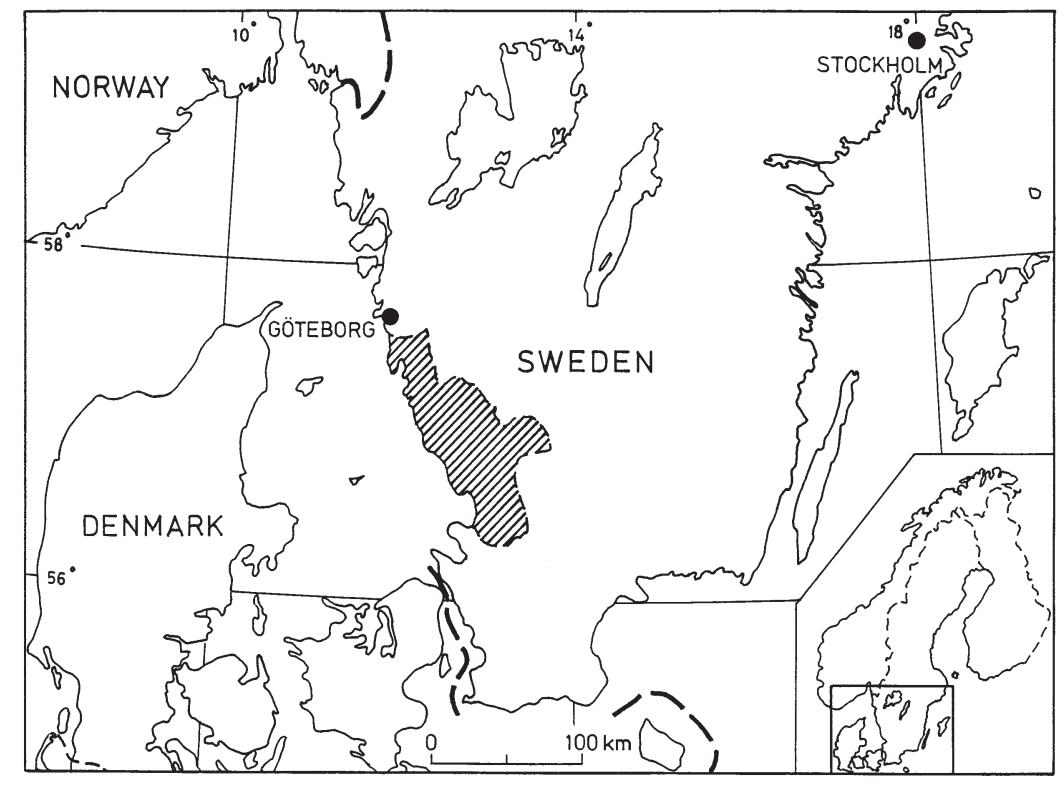

Fig. 1. Map showing southern Sweden and the area of investigation, the county of Halland 
The formation of hoarfrost is often associated with low visibility, due to high relative humidity. This is classified as a specific type of slipperiness (Type 5), as the low visibility may increase the traffic hazard. Type 6 results from a dewfall onto the road surface gradually changing into a hoarfrost event. When the road surface temperature drops below $0^{\circ} \mathrm{C}$, the already wet surface freezes and the hoarfrost further increases the ice cover.

Heavy sublimation of hoarfrost (Type 7) may occur when there is a large downward flux of water vapor. The expert system uses an empirical turbulence criterion to distinguish between heavy and weak formation of hoarfrost (Type 8) as the flux of water vapor is correlated to turbulence (Monteith \& Unsworth 1990).

For some situations it is important to study the previous weather conditions. Lindqvist (1979) presented 2 types of slipperiness: snowdrift (Type 9) and when water cover on the road surface freezes as $T_{\text {road }}$ falls below $0^{\circ} \mathrm{C}$ (Type 10). Snowdrift occurs when winds are strong and when there is snow with drifting potential in the surroundings. The criteria for this type of slipperiness are vague; the snow has to be dry enough and the wind has to be strong enough. The criteria used in the classification are the same as those used by the road authorities when deciding if there is need for maintenance activity (Vägverket 1996). When water on the road freezes as $T_{\text {road }}$ drops below $0^{\circ} \mathrm{C}$ (Type 10), the water source is generally water remaining from earlier rain or dewfall. This type of slipperiness uses criteria developed for the GAB-index (Gustavsson \& Bogren 1994), which is a model for the classification of winter climate.

The traffic accident data were taken from police reports compiled by the Swedish National Road Administration. The data set included all accidents, except those involving wildlife, on state roads (i.e. not streets in towns and cities, since they are a municipal responsibility). The reason for choosing police reports on which to base this study is that the exact time and place of each accident is given. This information is needed to connect the accident data to the other data sets. There are other sources of accident data which can be discussed in order to provide a more complete picture. Almost all accidents involving serious personal injuries and vehicle damage are reported to the police. However, there are a number of accidents, mostly causing less severe vehicle damage, which people find unnecessary to report. The number of reported traffic accidents in the 2 areas during the winter were 67 in 1991-92, 84 in 1993-94 and 95 in 1995-96.

The Swedish road network is divided into areas, each of which has one contractor responsible for WRM. The county of Halland (Fig. 1) is divided into 3 different areas. The contractors submit a report for every time they go out on the roads. In this report they note the time, place and type of action. As maintenance action can take several hours and traffic accidents are instant events, a day was divided into 4 different periods: morning, day, evening and night. If there had been any maintenance performed during the period in which the accident occurred, the road condition was considered as improved. Each working area archives their own maintenance reports on paper and maintenance data can therefore be difficult to access and interpret. Thus, only reports from the northern area and 2 seasons, 1993-94 and 1995-96, were used when analyzing the WRM.

The study areas are located in the coastal zone, which is mainly open agricultural lands with only some areas of higher forested terrain. The climate in this part of Sweden is, to a large extent, influenced by westerly winds, and during winters this results in a high frequency of passing low-pressure systems. Proximity to the sea is another factor that has a major influence on the regional climate of Halland. Monthly values of average air temperature and precipitation included in the accident and slipperiness comparison are presented in Fig. 2. The warmest winter, 1991-92, had a wet beginning and end. The winter of 1993-94 was also humid but not as warm. The last winter, 1995-96, was both the coldest and driest one. The final choice of these 3 winters was based on the different climatology and the WRM reports available.

\section{ANALYSIS AND RESULTS}

RWIS data from both areas and the 3 winter periods 1991-92, 1993-94 and 1995-96 were classified with the slipperiness classification. The number of hours with slippery roads was similar in both areas (Fig. 3).

The largest difference was found in December 1991, with 28 more hours in the north area. In both areas December, January and February had the most hours with slippery roads. The warm winter of 1991-92 (see Fig. 2) had large variations in the number of hours between months, while the cold and dry winter 199596 had more evenly distributed occasions of slipperiness.

When comparing the distribution of the most frequent types of slipperiness, each winter was clearly different from the others. Table 2 presents the number of hours with road slipperiness for each of the 10 types in the North area.

During the winter period of 1991-92 heavy formation of hoarfrost (Type 7) and hoarfrost formation with low visibility (Type 5) were the most common types in the North area. Precipitation (snow) on a frozen road surface (Type 2) and weak formation of hoarfrost (Type 8) 
were most frequent the winter 1993-94. Another common type during 1993-94 was precipitation (rain/sleet) on a frozen road surface (Type 1). Finally, the winter period 1995-96 differed from the other 2 in that slipperiness Types 2 and 7 were the most dominant.

Snowfall (Type 2) was generally most common in February, and strong hoarfrost (Type 7) was most common in December and January. Problematic situations with precipitation (rain or sleet) on a frozen road surface (Type 1) were also most common in December and January.

The distribution of traffic accidents between the 10 types of slipperiness was investigated by matching the classified RWIS data set with the time of traffic accidents for each area. The accident rate for each type of slipperiness was derived as the rate between the num-

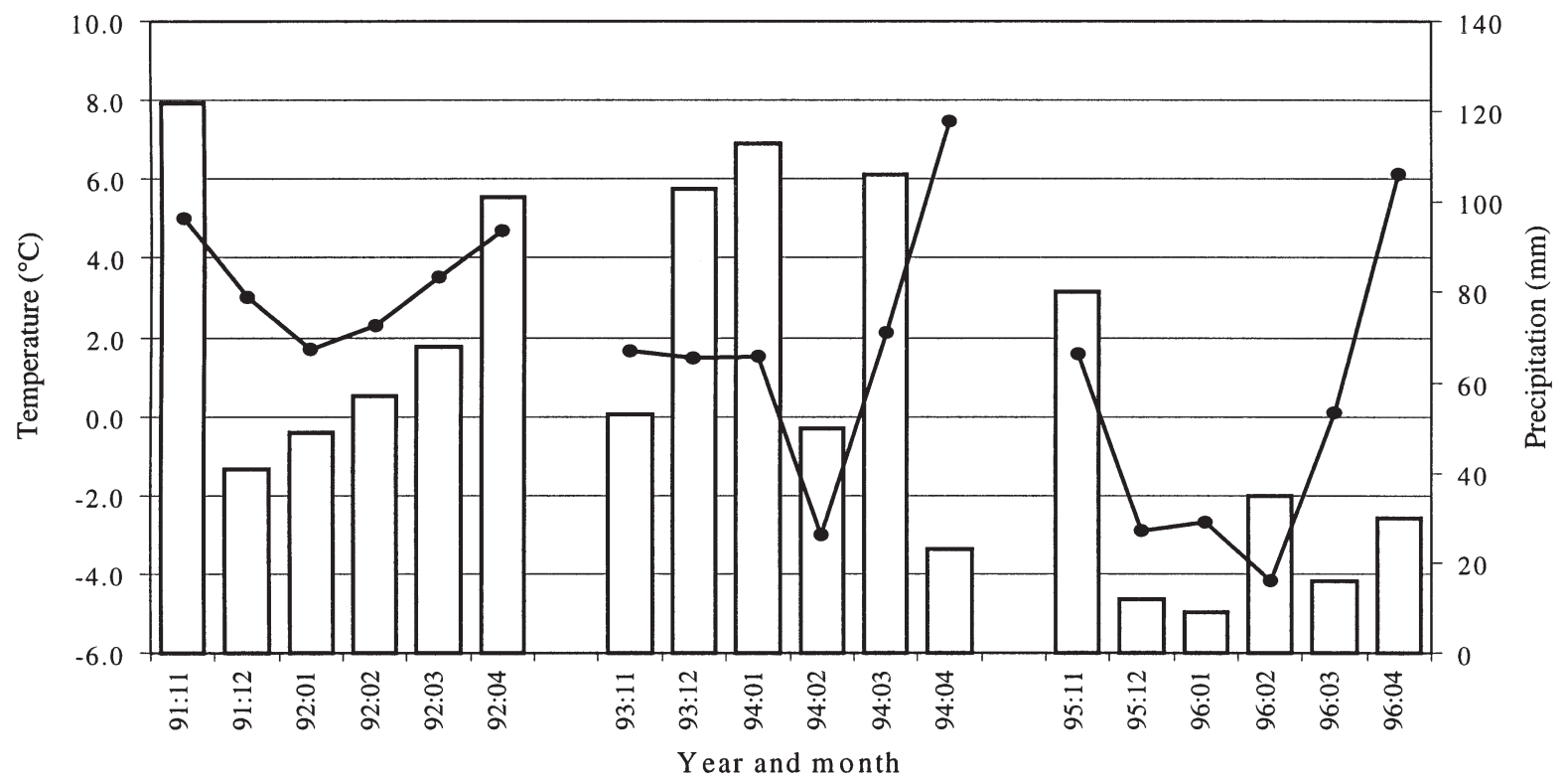

Fig. 2. Average monthly air temperature $\left({ }^{\circ} \mathrm{C}\right)$ and precipitation $(\mathrm{mm})$ for the winter periods of 1991-92, 1993-94 and 1995-96, SMHI station Varberg $\left(57^{\circ} \mathrm{N}, 12^{\circ} \mathrm{E}\right)$. Solid line represents air temperature and bars represent precipitation

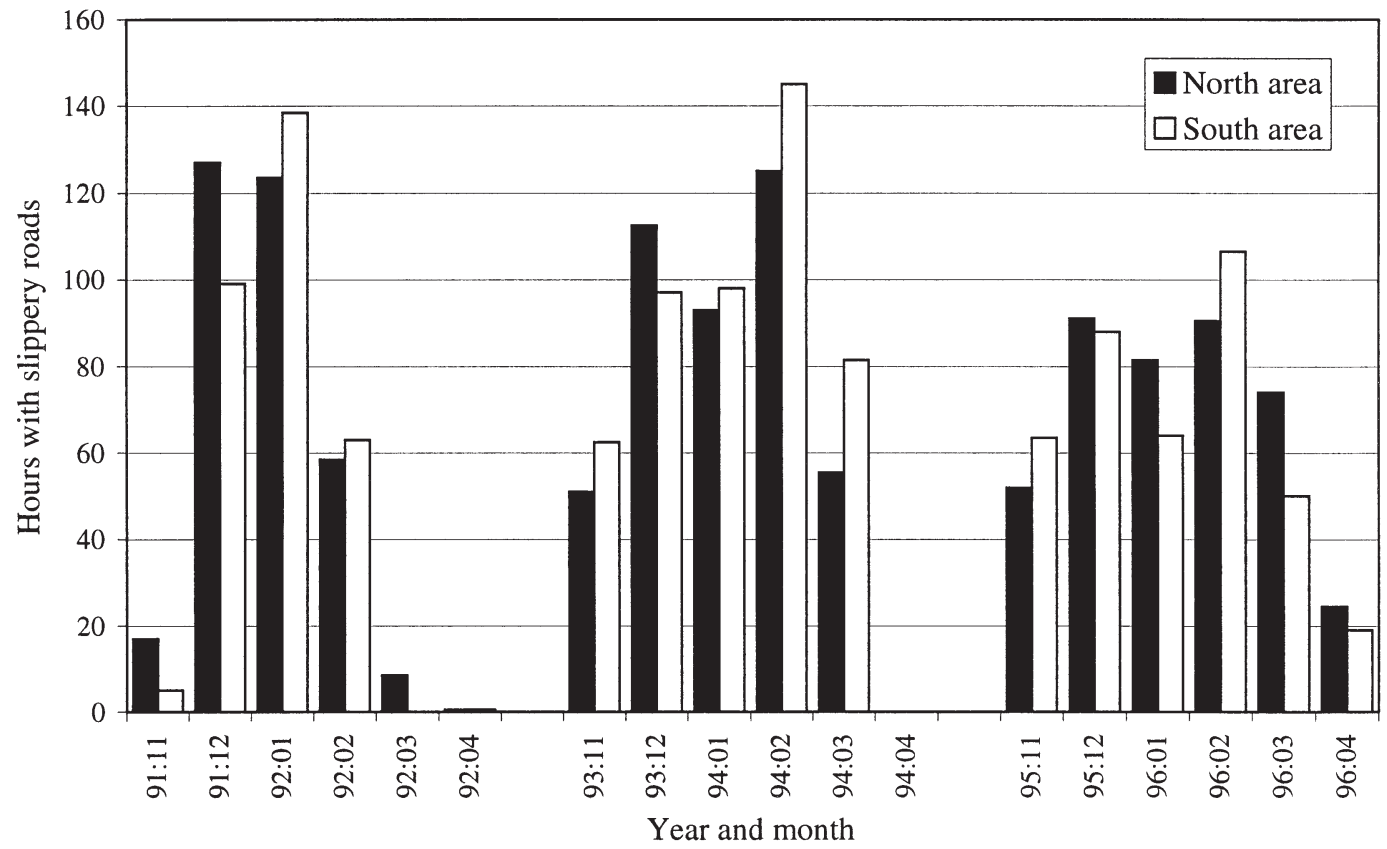

Fig. 3. Number of hours with slippery roads each month during 3 winter periods (1991-92, 1993-94, 1995-96) in the 2 study areas 
Table 2. Number of hours with road slipperiness (Types 1 to 10) each month during the 3 winters in the North area. For description of the different types of slipperiness see Table 1

\begin{tabular}{|c|c|c|c|c|c|c|c|c|c|c|c|c|c|c|c|c|c|c|}
\hline Type & $\begin{array}{c}1991 \\
11\end{array}$ & $\begin{array}{c}1991 \\
12\end{array}$ & $\begin{array}{c}1992 \\
01\end{array}$ & $\begin{array}{c}1992 \\
02\end{array}$ & $\begin{array}{c}1992 \\
03\end{array}$ & $\begin{array}{c}1992 \\
04\end{array}$ & $\begin{array}{c}1993 \\
11\end{array}$ & $\begin{array}{c}1993 \\
12\end{array}$ & $\begin{array}{c}1994 \\
01\end{array}$ & $\begin{array}{c}1994 \\
02\end{array}$ & $\begin{array}{c}1994 \\
03\end{array}$ & $\begin{array}{c}1994 \\
04\end{array}$ & $\begin{array}{c}1995 \\
11\end{array}$ & $\begin{array}{c}1995 \\
12\end{array}$ & $\begin{array}{c}1996 \\
01\end{array}$ & $\begin{array}{c}1996 \\
02\end{array}$ & $\begin{array}{c}1996 \\
03\end{array}$ & $\begin{array}{c}1996 \\
04\end{array}$ \\
\hline 1 & 0 & 4 & 3 & 3 & 2 & 0 & 7 & 16 & 13 & 8 & 9 & 0 & 2 & 9 & 10 & 4 & 1 & 0 \\
\hline 2 & 0 & 0 & 8 & 3 & 0 & 0 & 15 & 15 & 3 & 72 & 25 & 0 & 16 & 25 & 21 & 45 & 11 & 0 \\
\hline 3 & 0 & 0 & 20 & 2 & 1 & 0 & 3 & 0 & 0 & 8 & 0 & 0 & 7 & 0 & 0 & 0 & 1 & 1 \\
\hline 4 & 0 & 0 & 0 & 1 & 0 & 0 & 0 & 2 & 4 & 1 & 0 & 0 & 0 & 7 & 0 & 0 & 6 & 0 \\
\hline 5 & 13 & 71 & 48 & 13 & 0 & 1 & 2 & 14 & 10 & 1 & 10 & 0 & 0 & 0 & 0 & 0 & 24 & 23 \\
\hline 6 & 1 & 4 & 4 & 21 & 4 & 0 & 0 & 9 & 9 & 0 & 3 & 0 & 0 & 0 & 0 & 5 & 3 & 0 \\
\hline 7 & 1 & 37 & 33 & 11 & 2 & 0 & 1 & 7 & 3 & 4 & 0 & 0 & 16 & 37 & 51 & 12 & 25 & 2 \\
\hline 8 & 3 & 11 & 10 & 1 & 0 & 0 & 8 & 42 & 43 & 26 & 9 & 0 & 7 & 13 & 1 & 3 & 6 & 0 \\
\hline 9 & 0 & 0 & 0 & 0 & 0 & 0 & 15 & 0 & 0 & 6 & 0 & 0 & 6 & 1 & 0 & 23 & 0 & 0 \\
\hline 10 & 0 & 2 & 1 & 6 & 0 & 0 & 2 & 10 & 10 & 2 & 0 & 0 & 0 & 0 & 0 & 0 & 0 & 0 \\
\hline
\end{tabular}

ber of traffic accidents and the duration in hours. To find the accident risk for the type, $A_{\text {riskT, }}$ the accident rate was divided by the expected number of accidents. To derive an expected number of accidents, it was assumed that all accidents during a month, $A_{m}$, were evenly distributed events not affected by different road conditions. The average number of accidents per hour was $A_{m} / h_{m}$, where $h_{m}$ was the number of hours in that month. The expected number of accidents for each type of slipperiness was equal to the average number of accidents per hour multiplied by the duration of the slipperiness type. The ratio, $A_{\text {riskT, }}$ was calculated for all months and all types during the 3 different winter periods as follows:

$$
A_{\text {riskT }}=\frac{1}{N} \sum_{m=\text { Nov } 1991}^{\text {Apr } 1996} \mathrm{~A}_{t, m} h_{m}\left(A_{m} h_{t, m}\right)^{-1}
$$

where $A_{t, m}$ is the number of accidents per type of slipperiness $(t)$ and month $(m)$ and the number of hours

Table 3. Accident distribution on slippery road conditions and accident risk $\left(A_{\text {riskT }}\right)$ for each of slipperiness. The $A_{\text {riskT }}$ for non-slippery conditions is also included for comparison. The values include all 3 winters and are an average of the 2 areas

\begin{tabular}{|lcc|}
\hline Type & $\begin{array}{c}\text { Accident } \\
\text { distribution (\%) }\end{array}$ & $\begin{array}{c}\text { Accident } \\
\text { risk }\end{array}$ \\
\hline 1 & 13 & 11.6 \\
2 & 36 & 6.1 \\
3 & 6 & 3.4 \\
4 & 6 & 6.4 \\
5 & 8 & 1.5 \\
6 & 2 & 3.2 \\
7 & 12 & 2.5 \\
8 & 11 & 4.5 \\
9 & 5 & 1.5 \\
10 & 1 & 2.6 \\
Non-slippery & & 0.7 \\
\hline
\end{tabular}

with the type of slipperiness is denoted $h_{t, m}$. $N$ is the number of months, 18 in this study.

If $A_{\text {riskT }}$ is 1 , the number of traffic accidents occurring during that type is the same as the expected number of accidents. If the $A_{\text {riskT }}$ is larger than 1 , more traffic accidents occur than expected if evenly distributed.

Table 3 presents the categories 'accident distribution' and 'accident risk' for each type of slipperiness. The largest number of traffic accidents occurred during precipitation (snow) on a frozen road surface (Type 2), and precipitation (rain or sleet) on a frozen road surface (Type 1). Slipperiness due to Type 1 also had the highest accident risk, which indicates that this is a hazardous situation. The second most hazardous road condition is when snowfall and hoarfrost formation occurs at the same time (Type 4). The data in Table 3 is based on a total of 246 accidents, of which 83 occurred when road conditions were classified as slippery.

The classification of road condition at the time of accidents was compared with the road surface statements in the accident reports. Three different statements in the accident reports described slippery road conditions: thin ice, thick ice and loose snow. The contingency table in Table 4 presents the relationship between the 2 data sets.

Table 4. Contingency table relating classified RWIS data and road surface statements in accidents reports, based on accident data from both the North and South areas, 1991-92, 1993-94 and 1995-96. The average slipperiness relationship between accidents and slippery road conditions is $113 / 246=0.46$

\begin{tabular}{|lccr|}
\hline $\begin{array}{l}\text { Accident } \\
\text { reports }\end{array}$ & Slippery & $\begin{array}{c}\text { Classified RWIS data } \\
\text { Not slippery }\end{array}$ & Total \\
\hline Slippery & 56 & 30 & 86 \\
Not slippery & 27 & 153 & 180 \\
Total & 83 & 183 & 246 \\
\hline
\end{tabular}


Table 5. Contingency table and statistics based on classified RWIS data and maintenance reports from the North area. The data are based on 4 periods in each day during 2 winter seasons, 1993-94 and 1995-96. See text for description of statistics. POD: probability of detection

\begin{tabular}{|lccc|}
\hline \multirow{2}{*}{$\begin{array}{l}\text { WRM } \\
\text { reports }\end{array}$} & Slippery & Not slippery & Total \\
\hline Maintenance & 145 & 109 & 3254 \\
No maintenance & 153 & 1045 & 1198 \\
Total & 298 & 1154 & 1452 \\
Occurrence (\%) & 21 & & \\
POD $(\%)$ & 49 & & \\
\hline
\end{tabular}

Table 6. Lag analysis of WRM actions the period before an accident and at the time of an accident when the road was classified as slippery. The analysis is based on data from the North area, 1993-94 and 1995-96

\begin{tabular}{|lcc|}
\hline Period of WRM & No. of accidents & Percentage \\
\hline Previous & 4 & 11 \\
Previous and coincident & 10 & 29 \\
Coincident & 17 & 49 \\
No WRM & 4 & 11 \\
\hline
\end{tabular}

Of all 246 accidents during the 3 winters, $50 \%$ were related to slippery road conditions either in the accident reports or by the classification. Seventy percent of the situations classified as slippery from RWIS data were verified by the statements in the accident reports. On the occasions when accident reports stated that the road condition was slippery but the RWIS did not, the problem was often due to loose snow.

Winter road maintenance reports from the 2 winters in the northern area, 1993-94 and 1995-96, were compared with classified RWIS data and accident rates. A contingency table of the comparison of the RWIS data and the maintenance reports (Table 5) shows that on $21 \%$ of all day periods during the 2 winters, road conditions were classified as slippery. The number of day periods with RWIS observations classified as slippery was slightly larger than the number of day periods with WRM activity. WRM took place on $49 \%$ of these periods with slipperiness (POD, probability of detection). One reason for the difference is that maintenance is often performed preventively, based on a weather forecast.

The temporal distributions of WRM activities compared to accident times were investigated with a lag analysis (Table 6). The lag analysis showed that WRM was performed both during the previous period and the coincident period for $30 \%$ of all accidents. For $50 \%$ of the accidents WRM was performed during the coincident period.
Table 7. Contingency table statistics for the types of slipperiness and WRM periods. The last column represents WRM activity when accidents occurred. The data are based on 4 periods in each day during 2 winter seasons 1993-94 and 1995-96. For a description of the different types of slipperiness, see Table 1

\begin{tabular}{|lccc|}
\hline Type & Occurrence (\%) & POD (\%) & $\begin{array}{c}\text { WRM when } \\
\text { accidents (\%) }\end{array}$ \\
\hline 1 & 2.1 & 65 & 100 \\
2 & 6.3 & 55 & 65 \\
3 & 0.4 & 42 & No accidents \\
4 & 0.7 & 65 & 100 \\
5 & 2.5 & 24 & 50 \\
6 & 0.3 & 69 & No accidents \\
7 & 6.6 & 42 & 100 \\
8 & 0.6 & 39 & 100 \\
9 & 1.0 & 54 & 50 \\
10 & 0.0 & 60 & 100 \\
\hline
\end{tabular}

Contingency table statistics were also derived for each type of slipperiness (Table 7). The most common types of slipperiness during the 2 winters of 1993-94 and 1995-96 were heavy formation of hoarfrost (Type 7) which occurred in $7 \%$ of all periods. Precipitation (snow) on a frozen road surface (Type 2) was almost as common with $6 \%$ of all periods. The type of slipperiness with highest maintenance activity (POD) was freezing dew followed by hoarfrost (Type 6), with WRM occurring on $70 \%$ of the classified occasions. Precipitation (rain/sleet) on a frozen road surface (Type 1) and snowfall together with hoarfrost (Type 4) also had a POD larger than $60 \%$. Type 1 and Type 4 also had the highest accident rates together with Type 2 (Table 3).

The category 'WRM when accidents' (Table 7) describes the maintenance activity on each type of slipperiness at the times of accidents. Maintenance activity is defined as the ratio of 'the number of occasions with maintenance at the time of a traffic accident' divided by 'the total number of traffic accidents on that type of slipperiness.' At the times of the accidents during the 2 types with highest $A_{\text {riskT, }}$ Types 1 and 4 in Table 3 , there was $100 \%$ maintenance. That is, even with full maintenance activity, traffic accidents still occurred during these types of slipperiness. Of all traffic accidents on slippery roads during the 3 years, most accidents happened during snowfall, Type 2 in Table 3. On these occasions POD was $55 \%$ and the maintenance when accidents occurred was $65 \%$, which indicates that the WRM could be increased.

\section{DISCUSSION}

This study presents a method for deriving quantitative relationships between road slipperiness, traffic 
accident risks and WRM activity; it is applied in an area where WRM is performed to increase road safety. Since reducing the number of traffic accidents related to road slipperiness is of major concern for national road administrators, it is important to evaluate the effect of maintenance continuously.

The study showed that in most situations when an accident occurred on slippery roads there was full WRM activity. This indicates that during these episodes, WRM is not enough to maintain traffic safety. Other actions in combination with WRM are necessary to reduce the number of accidents. One possible way to decrease $A_{\text {riskT }}$ during these situations is to increase the public awareness, either by information signs or by temporarily lowering the speed limits.

The results from the test area showed that there are differences in $A_{\text {riskT }}$ between the 10 types of slipperiness (Table 3 ). A large $A_{\text {riskT }}$ and full WRM activity at the time of accidents indicate that the public awareness must be increased in situations with these types of road slipperiness. The $A_{\text {riskT }}$ might not be representative due to the relatively low number of accidents used in the study; 83 out of 246 accidents were classified from the RWIS data as slippery. A result that supports the representativity of the $A_{\text {riskT }}$ is that precipitation (rain or sleet) on a frozen road surface (Type 1) received the highest accident rate. It is not only hazardous due to the low friction but also because it may develop very quickly and is hard to detect visually.

Precipitation (snow) on a frozen road surface (Type 2) and snowfall together with hoarfrost (Type 4) received high $A_{\text {riskT }}$ even though these conditions are clearly visible. This also supports the statement that accident risk during different road conditions is also a function of the public awareness of the problem (Johansson 1997, Edwards 1999). Other studies have found the same result, that drivers are not good at adjusting the speed of their vehicle to the prevailing road conditions, even if the hazard, for example, snow, is clearly visible (Öberg 1991, Wallman 1997).

A factor that may have caused errors in this relationship is the spatial variation of road conditions. Only 2 RWIS stations were used in the study, and it is possible that on some occasions the classified road conditions were not the same as those at the site of the accident. Most of the slipperiness types develop over larger areas, which makes this error small, but weak formation of hoarfrost, for example, could develop locally.

Restrictions to applying this method in other countries are the availability and organization of the input data: RWIS, traffic accident reports and WRM reports. The largest problem in Sweden is that the maintenance reports, which do not yet use a standard system, are written on paper and are archived locally in each working area. However, some areas have started to use a computerized filing system. These problems were the reason why only 2 seasons of data from 1 working area were used when developing and testing the method. Increasing the study to more working areas would not improve the point of this study, that a continuous evaluation of traffic accidents on slippery roads is very important for traffic safety. The data necessary for this evaluation must be organized in easily comparable formats based on a standardized road slipperiness classification.

\section{CONCLUSIONS}

During the 3 winters studied in Halland, road conditions are classified as slippery 2 to $4 \mathrm{~h} \mathrm{~d}^{-1}$ on average. Generally, road slipperiness is induced by hoarfrost at the beginning of the season and by snowfall in the middle of the season, while the situation at the end of the season may vary between years.

The largest number of traffic accidents occurred during precipitation (snow) on a frozen road surface (Type 2), but precipitation (rain or sleet) on a frozen road surface (Type 1) received the highest accident risk. Snowfall and frost formation occurring together (Type 4) and Type 2 received the second highest accident risk.

Of all 246 accidents during the 3 winters, $50 \%$ were related to slippery road conditions either in the accident reports or by the classification. Twenty percent of the accidents were verified as slipperiness related, both by the accident reports and the classified RWIS data.

At the time of the accidents during the 2 types of slipperiness with highest $A_{\text {riskT }}$, Type 1 and Type 4, there was $100 \%$ WRM activity. That is, even with full maintenance activity, traffic accidents still occurred. This clearly suggests that in order to reduce the number of accidents during these situations public awareness must be increased. This can only be accomplished by providing information about road conditions to the drivers, probably also with reduced-speed recommendations. Introducing a system for presenting information to drivers cannot practically be done in one working area alone, due to the large costs for creating such a system. By investigating which types of slipperiness are most problematic and where they are most frequent, it would be possible to identify areas where an information system is most needed.

The study also demonstrates the benefits of applying a standardized road slipperiness classification to all sources for road safety information: RWIS, traffic accident reports and WRM reports. With a standardized and objective classification of the road conditions and 


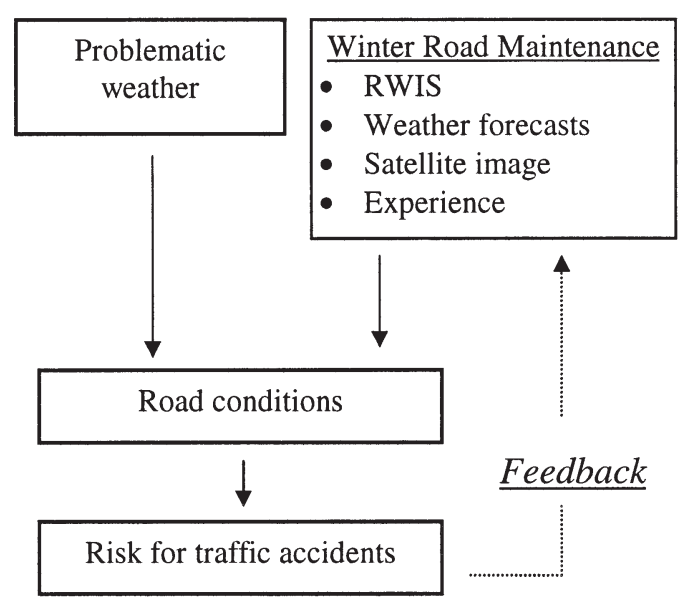

Fig. 4. A flow chart showing the impact of weather on road conditions and traffic accidents. Winter road maintenance is performed to improve the road conditions, which in turn decreases the number of accidents. How well this works is presented in the feedback

digitally stored data, all evaluations are easily conducted.

The method presented in this study is not restricted to traffic accidents only. To perform other evaluations only data in one of the boxes in Fig. 4 need be changed.

In the flow chart, problematic weather may have a negative impact on the road conditions, and thus the risk for traffic accidents due to road slipperiness increases. The WRM personnel analyze the prevailing road conditions based on their own experience and by using different types of derived information. If they consider the situation to be hazardous they take the necessary action and improve the road conditions to reduce the accident risk. If the method presented in this study is applied, the accident risks and the WRM activity for the 10 types of road slipperiness can be used as feedback information, which can indicate how to further increase the road safety.

Examples of other evaluations in which this method can be used include: the effect of speed reduction instead of winter road maintenance or traffic flow instead of traffic accidents. This is possible as long as the road condition is classified with a standardized set of slipperiness types.

Editorial responsibility: Laurence Kalkstein, Newark, Delaware, USA
Acknowledgements. This project was sponsored by The Swedish Transport \& Communications Research Board. The authors would like to thank Assistant Prof. Torbjörn Gustavsson and Dr Jörgen Bogren for comments on a draft of this paper. We also thank Tomas Bergbom at the Swedish National Road Administration (SNRA), Göteborg, for helping with the traffic accident data and the personnal at SNRA, Varberg, for the WRM reports. The authors would also like to thank the reviewers for their comments and useful suggestions for improvement of the manuscript.

\section{LITERATURE CITED}

Andreescu MP, Frost DB (1998) Weather and traffic accidents in Montreal, Canada. Clim Res 9:225-230

Andrey J, Olley R (1990) Relations between weather and road safety: past and future research directions. Climatol Bull 24(3):123-137

Edwards J (1999) The temporal distribution of road accidents in adverse weather. Meteorol Appl 6:59-68

Fridstrøm L, Ifver J, Ingebrigtsen S, Kulmala R, KrogsgårdThomsen L (1995) Measuring the contribution of randomness, exposure, weather and daylight to the variation in road accident counts. Accident Anal Prev 27(1):1-20

Gustavsson T (1995) A study of air and road-surface temperature variations during clear windy nights. Int J Climatol 15:919-932

Gustavsson T, Bogren J (1994) The GAB Index - a model for the classification of winter climate. In: Brázdil R, Kolář M (eds) Proceedings of the Meeting of the Commission on Climatology of the International Geographical Union, 15-20 August 1994, Brno, p 238-242

Johansson Ö (1997) Olycksutfall och skadeutfall vintertid. En jämförelse av olyckor under 3 vintrar med helt olika klimatbetingelser. Vägverket Publ 1997:50

Kulmala R, Rämä P (1995) The effects of weather and road condition warnings on driver behaviour. Proceedings of the Conference on Road Safety in Europe and Strategic Highway Research Program (SHRP), Prague, p 169-178

Lindqvist S (1979) Studies of slipperiness on roads. GUNI report 12, Dept of Physical Geography, Göteborg, p 1-46 (in Swedish with English abstract)

Monteith JL, Unsworth MH (1990) Principles of environmental physics, 2nd edn. Edward Arnold, London

Norrman J (2000) Slipperiness on roads-an expert system classification. Meterol Appl 7:27-36

Öberg G (1991) More effective de-icing with less salt. VTI Rapport 369 (in Swedish with English abstract)

Öberg G (1993) Traffic on ice and snow. Nordic Road Transport Res 3:32-33

Sävenhed H (1995) Samband mellan vinterväghållning och trafiksäkerhet. VTI Rapport 399:58

Schandersson R (1988) Samband mellan trafikolyckor, väglag och vinterväghållningsåtgärder. VTI Meddelande 514:53

Vägverket (1996) Drift 96. Vägverket, Publ 1996:016

Wallman CG (1997) Driver behaviour on winter roads a driving simulation study. VTI Rapport 419A

Submitted: April 15, 1999; Accepted: March 2, 2000

Proofs received from author(s): July 24, 2000 